\title{
DESIGN AND DEVELOPMENT OF NOVEL FLEXIBLE BISMALEIMIDE TOUGHENED MULTI-WALLED CARBON NANOTUBE REINFORCED EPOXY NANOCOMPOSITES
}

\author{
M. Soundarrajan ${ }^{1}$, L. Devaraj Stephen ${ }^{1}$ and S.G.Gunasekaran ${ }^{1,2, *}$ \\ ${ }^{1}$ Department of Chemistry, Valliammai Engineering College, SRM Nagar, Kattankulathur, \\ Kancheepuram-603203, India. \\ ${ }^{2}$ Department of Applied Science and Technology, Anna University, Chennai-600025, India. \\ *E-mail: gunasekaransg.chemistry@valliammai.co.in
}

\begin{abstract}
A novel water-soluble and flexible aliphatic bismaleimide resin (BMIDPE) was synthesized by using maleic anhydride and polyether diamine (PEA) and toughened with diglycidyl ether of bisphenol-A (DGEBA) with 4,4'diamino diphenyl methane (DDM) as curing agent. This BMIDPE toughened DGEBA were further altered with various weight percentages $(0.5,1.0 \& 1.5 \mathrm{wt} \%)$ of multi-walled carbon nanotube (MWCNT) to obtain MWCNT/BMIDPE/DGEBA nanocomposites. The thermal studies indicated that the MWCNT/DGEBA nanocomposites displayed improved thermal stability and decreased the glass transition temperature $\left(T_{g}\right)$ than that of the neat epoxy matrix. The prepared nanocomposites displayed a better dielectric constant than that of the neat epoxy system. From XRD data, it is observed that MWCNT was exfoliated into BMIDPE toughened epoxy. The homogeneous fine dispersion of MWCNTs throughout the DGEBA matrix was ascertained by SEM. The result from mechanical analysis specifies that the inclusion of PEA into the epoxy system increases the toughness. Moreover, it was believed that this new type of BMIDPE toughened DGEBA/MWCNT nanocomposites would be utilized for high-performance applications.

Keywords: Carbon nanotube, flexible-bismaleimide, epoxy, thermal, electrical, mechanical and morphological properties.
\end{abstract}

(C) RASĀYAN. All rights reserved

\section{INTRODUCTION}

MWCNTs are attractive building blocks consisting of multiple concentric graphene cylinders with unique structure and properties ${ }^{1}$. Their exceptional electrical, thermal and mechanical properties were making them ideal composite reinforcement material ${ }^{2-4}$, hydrogen containers ${ }^{5}$, field emission sources ${ }^{6}$, supercapacitors $^{7}$, molecular sensors ${ }^{8}$ and scanning probe tips ${ }^{9}$. The current investigations have widely concentrated on the carbon nanotube reinforced epoxy resin nanocomposites as a result of their widespread applications in the aeronautics, astronautics and electronics industries ${ }^{10}$. However, the reinforcement role of CNTs in epoxy-based nanocomposites seems divergent. Some previous research reported the properties of carbon nanotube reinforced epoxy nanocomposites compared with the neat epoxy system ${ }^{11-13}$. Contributing attractive thermal/electric/mechanical properties, CNTs could represent a classical system for assessment of the potential to achieve a substantial improvement in comprehensive properties by adding nanoscale modulators at low weight percent.

Epoxy matrix is a versatile and extensively accepted resin used most frequently reinforced with nanotubes for unconventional composite uses, sealants, electronic circuit board materials, radomes hardware components and missile equipment components ${ }^{14}$. The resins of this class have dimensional stability, good stiffness, specific strength and chemical resistance and also display significant adhesion to the embedded matrix ${ }^{15}$. Many types of filler such as nanotubes, nanofibres and nanoparticles are now being tried as reinforcement material to produce better performance epoxy structures with increased properties $^{16}$.

Rasayan J. Chem., 12(1), 168-183(2019)

http://dx.doi.org/10.31788/RJC.2019.1214083

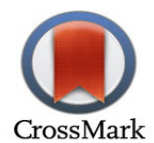


For improving its working performance in high-end engineering applications, chemical functionalization of the epoxy matrix has been primarily done to increase the impact resistance. Polymeric materials with flexible linkages such as carboxyl group-terminated acrylonitrile-butadiene (CTBN), hydroxyl-terminated acrylonitrile-butadiene (HTBN), amine-terminated acrylonitrile-butadiene (ATBN), polyacrylates and nitriles have generally been employed as impact converters used for epoxy matrices ${ }^{17}$. However, the modified epoxy resin can be brought its application well connected with corrosion coatings, weather resistant and structural adhesives. It was noted that the siloxane moiety incorporated epoxy matrix enhances the impacts owing to stress-strain properties of a minor change in glass transition behavior ${ }^{18,19}$. Progressiveness in thermo-mechanical behaviors was attained due to the inclusion of BMI core into epoxy matrix ${ }^{20-24}$, siliconized epoxy ${ }^{25}$ and unsaturated polyester resin ${ }^{26}$.

BMIs are considered as a class of better temperature withstanding thermoset like polyimides and they find a wide range of applications in aerospace and electronics industries ${ }^{27}$. They hold high $T_{g}$, high char yield, high cross-linking ability, superior and specific modulus, low water absorption, excellent fire resistance, specific strength and high thermal stability ${ }^{28}$. The necessity of bismaleimide arose since the epoxies possess poor hot/wet performance in terms of applications. And, BMI linkages are capable to fabricate epoxy matrices and reveal capability of performing temperatures up to $230^{\circ} \mathrm{C}^{29}$. Though, the cured matrices are breakable owing to their aromatic structure and the high cross linking density of the network. Several efforts have been completed to increase the impact and fracture toughness of bismaleimide materials. Wang and his co-workers studied the introduction of the extended chain in the backbone of bismaleimide to decrease crosslink density ${ }^{30}$. Several investigators have efforted to subdue the inelastic nature of BMI through alteration of chemical configuration by including additional chemical groups ${ }^{31}$. One of the effective methods is done by using the high-molecular-weight prepolymers with chainextension obtained via Michael addition synthesis reaction between diamine and $\mathrm{BMI}^{32}$. This is an efficient method of decreasing the brittleness of BMIs and the process will outcome the chain extended BMI-amine adduct to form the cross-linking structure. Also diamines and dithiols are the preferred bisnucleophilic chain-extender since they have high basicity ${ }^{33-35}$. They reduce the brittleness of BMI because of their superior polymer segments which are offered core molecular movement after cross-linking. The crystallinity experimented for the developed MDA-modified BMI systems and its CNT composites ${ }^{35}$. There still a major disadvantage of using BMIs is difficulty in processing due to extremely aromatic chemical structures. In recent times, bismaleimides that have flexible bonds are commonly used as heat proof materials ${ }^{36,37}$. But the introduction of flexible networks into the bismaleimide monomers reduce the crosslink density ${ }^{38,39}$ and thus resulted in the depressing of $T_{g}$ and also the decomposition behavior of the final cured composite products. Consequently, a periodic analysis is requisite for considering the properties such as processibility, mechanical properties, morphology and crystallinity of the matrix and the carbon nanotubes reinforced nanocomposites.

In this context, a new type of chain extended BMI using a polyether amine, Jeffamine ED 2003, has been designed and BMI toughened epoxy/MWCNT nanocomposites were prepared and characterized their structure, thermal stability, crystallinity, mechanical and morphology properties.

\section{EXPERIMENTAL}

\section{Materials}

Bundled MWCNTs were purchased from Applied Science and Innovation Pvt. Ltd, Pune, India. The special surface areas were $40-500 \mathrm{~m}^{2} / \mathrm{g}$ and their lengths were $1.0-40 \mu \mathrm{m}$ and diameter of the MWCNTs was $20-45 \mathrm{~nm}$. The received MWCNTs were treated by nitric acid and sulphuric acid and refluxed for 24 $\mathrm{h}$, which as per the procedure reported ${ }^{40}$. The raw material such as DGEBA (LY556 equivalent [E] weight: 187) and 4, 4-diaminodiphenylmethane (DDM) was also bought from Huntsman Ltd India. Polyetherdiamine (Jeffamine ED 2003) M.Wt:2000, maleic anhydride (Fluka, 99\%), acetone (Baker), acetic anhydride (B.D.H, UK) and N, N-dimethylformamide (DMF, SRL). All reagents were used without further purification except acetone and DMF, which were lately dried by standing over freshly, renewed type $4 \AA$ molecular sieves for $24 \mathrm{~h}$. Novel BMIDPEDPE was produced as per the reported method. 


\section{Functionalization of MWCNTs}

The reason for functionalization was the debundling and dispersion improvement of the nanotubes during composite processing. Thus, the functionalization process was made in two steps: firstly, the oxidation of MWNT using a 3:1 (vol.) mixture of $\mathrm{H}_{2} \mathrm{SO}_{4}$ : $\mathrm{HNO}_{3}$ in order to purify the raw material from catalyst traces, to obtain carboxylic groups on their surface, as well as at the end by capping the semispherical ends. Thus $100 \mathrm{mg}$ of MWNTs was added to $12 \mathrm{ml} \mathrm{H}_{2} \mathrm{SO}_{4}: \mathrm{HNO}_{3}$ mixture, heated at $70^{\circ} \mathrm{C}$ in silicon oil bath and kept under stirring for $12 \mathrm{~h}$ and then the product was filtrated on $0.22 \mu \mathrm{m}$ pore Teflon membrane and washed until the $\mathrm{pH}$ reached neutral value and dried at for $48 \mathrm{~h}$ at room temperature $(\mathrm{RT})^{40}$ to yield (MWNT-COOH).

\section{Synthesis of Bis-maleimidodiaminopolyether (BMIDPE)}

A three-way RB flask purged with nitrogen fitted out with a dropping funnel and a solution of polyetherdiamine (Jeffamine ED 2003) $(20,0.01 \mathrm{~mol})$ in $8 \mathrm{ml}$ of acetone ${ }^{28,41,42}$ were poured as per the procedure reported somewhere (Scheme-1).

The RB flask was cleaned with $\mathrm{N}_{2}$ and then maleic anhydride solution $(1.96 \mathrm{~g}, 0.022 \mathrm{~mol})$ in $10 \mathrm{ml}$ of acetone was further added dropwise to the above blend. The reaction released excess heat (exothermic), the addition was subsequently done in a water/ice bath. This mixture was then stirred well for $4 \mathrm{~h}$ at 0 $5^{\circ} \mathrm{C}$ and at room temperature for an extra $1 \mathrm{~h}$.

The above solution was then refluxed with a preheated solution $\left(60-65^{\circ} \mathrm{C}\right)$ of sodium acetate $(0.1 \mathrm{~g})$, acetic anhydride $(10 \mathrm{ml})$ and triethylamine $(2 \mathrm{ml})$ were further added to the preheated solution and the reaction product was agitated for $6 \mathrm{~h}$. The solution was later cooled to RT and then slowly added into ice water on stirring. The mixture was further stirred and allowed the tin salts to completely hydrolyze by adjusting the $\mathrm{pH}$ to basic with the addition of sodium bicarbonate (5\%). The aqueous solution was then separated with extra $\mathrm{CHCl}_{3}$ and carefully washed with brine solution and dried using sodium sulphate. Evaporation of the additional solvent leaves a dark brown viscous liquid with a yield of $85 \%$ (Scheme-1).

\section{Preparation of Blends}

The DGEBA/BMIDPE blends were prepared by mix blending technique, and their compositions are shown in Table-1. The obtained blends were cured with aromatic amine curing agent DDM in a stoichiometric amount equivalent to epoxy resin. The reaction was carried out in a thermostatic oil bath to maintain the constant temperature. Initially, the BMIDPE resins were weighed and dissolved in the absence of a solvent with the pre-weighed quantity of liquid epoxy matrix at a temperature of $120^{\circ} \mathrm{C}$ for 2 $\mathrm{h}^{13}$. After, the desired amount of curing agent (dried at $80^{\circ} \mathrm{C}$ ) was added into the synthesized blend and mixed with help of stirrer because polymer starts to become gel above this temperature, until ensuring the homogenous and visually transparent mixture.

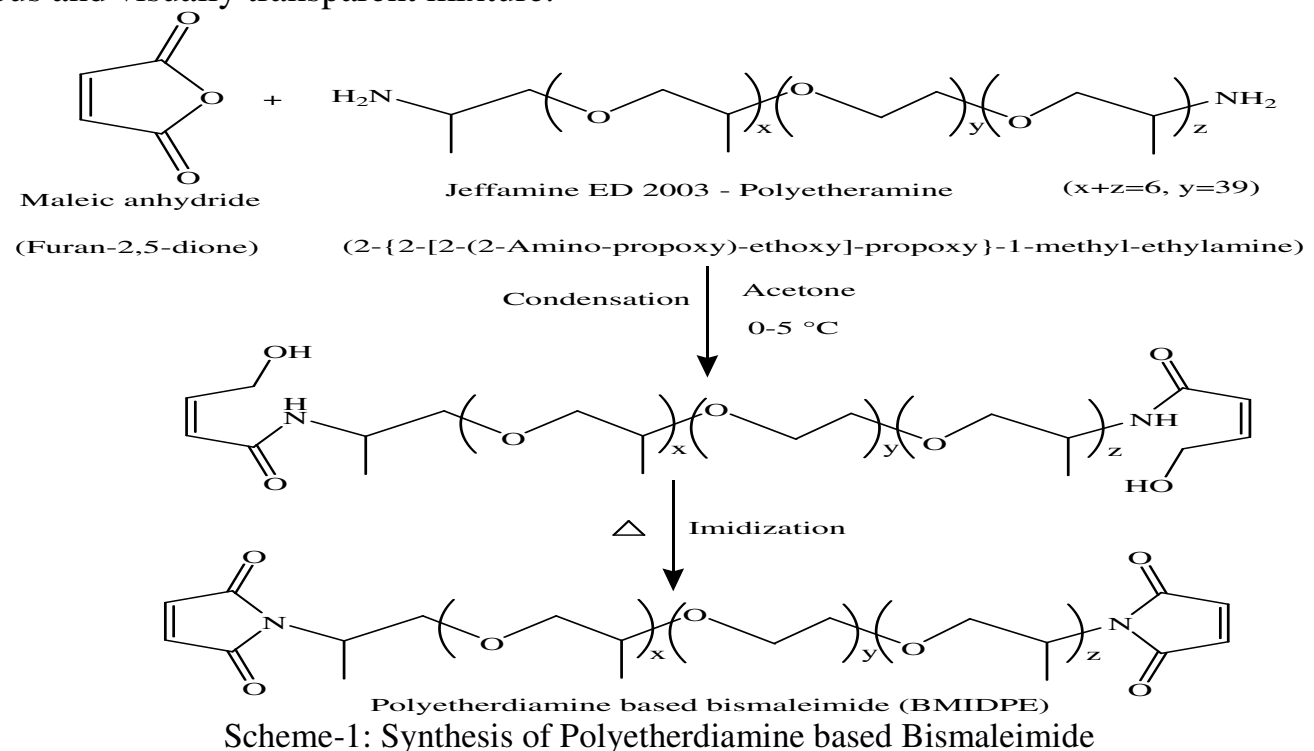


RASĀYAN J. Chem.

Vol. 12 | No. 1 |168 - 183| January - March | 2019

\section{Casting of Composites}

Composites were obtained by mixing a stoichiometric quantity of the curative agent DDM respective to DGEBA/BMIDPE and blended with the (MWNT-COOH at RT ${ }^{43}$.
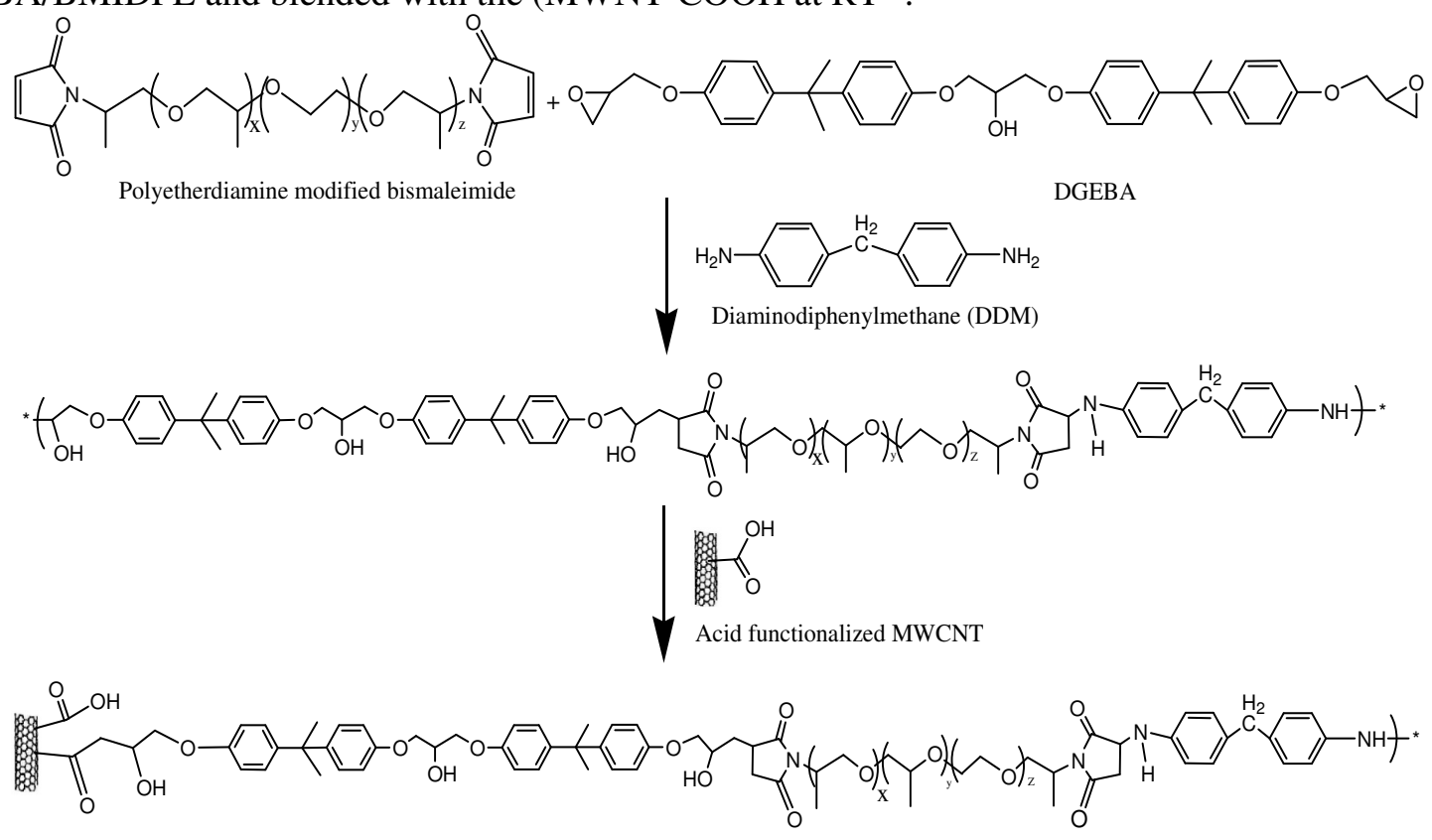

Polyetherdiamine modified bismaleimide based Epoxy/MWCNT nanocomposite

Scheme-2: Schematic representation of Synthesis of the BMIDPE/DGEBA/MWCNT Nanocomposites

Prior to Curing, the trapped Air from Product was eliminated by Vacuum. The Curing Process was carried in Two Steps Thermal Treatment: One Step for $3 \mathrm{~h}$ at $120^{\circ} \mathrm{C}$ and the Later Step for $2 \mathrm{~h}$ at $180^{\circ} \mathrm{C}$ to Complete this Reaction.

The method used to obtain the epoxy/MWNTs nanocomposites samples is illustrated in Scheme-2. The casting was then lastly detached from the mould and studied their properties.

\section{Characterization}

\section{Physicochemical Studies}

Fourier Transform (FT-IR) infrared spectral data of MWCNT incorporated Epoxy nanocomposites were recorded between 400 and $4000 \mathrm{~cm}^{-1}$ on a Perkin Elmer 6X FT-IR spectrophotometer. Approximately 100 $\mathrm{mg}$ of optical-grade $\mathrm{KBr}$ was finely ground with the adequate amount of the polymer sample to make 1.0 wt $\%$ mixture for making $\mathrm{KBr}$ pellets. At least 16 scans were made for all samples at a resolution of \pm 4 $\mathrm{cm}^{-1}$ after the sample was loaded. JEOL $500 \mathrm{MHz}$ NMR spectrometer was employed to record ${ }^{1} \mathrm{H}$ and ${ }^{13} \mathrm{C}$ NMR analyses. Samples were diluted and analyzed by using $\mathrm{CDCl}_{3}$ and TMS as an internal standard.

\section{Thermal Studies}

A differential scanning calorimeter (DSC-200, Netzsch) in the temperature range between 50 and $400^{\circ} \mathrm{C}$ at a heating rate of $10^{\circ} \mathrm{C} \mathrm{min}-1$ was used to determine the glass transition temperature $\left(T_{g}\right)$ of the samples under a constant flow of nitrogen. Thermal analysis (TGA) was also carried out in a DSC-2920 from TA Instruments combined with a TA-2000 control system. The calibration of the instrument was done using calcium oxalate and aluminum delivered by Netzsch. The samples (about $50 \mathrm{mg}$ ) were heated up to $80^{\circ} \mathrm{C}$ under a continuous supply of nitrogen $\left(60 \mathrm{~mL} \mathrm{~min}^{-1}\right)$, at $10^{\circ} \mathrm{C} \mathrm{min}^{-1}$.

\section{X-Ray Diffraction Studies}

Wide-angle X-ray spectra were obtained using an X'Pert PRO PANalytical (Model 3000) diffractometer (with $\mathrm{Cu} \mathrm{K} \mathrm{K}_{\propto}$ radiation $(\theta=0.15406 \mathrm{~nm})$ for the ground powder of cured composites. The spectral window ranged from $2 \theta=0^{\circ}$ to $70^{\circ}$. 


\section{Water Absorption Behavior}

ASTM D 570 was used to test the water absorption properties of the nanocomposite films. The nanocomposite specimens (dimensions: $100 \mathrm{~mm}$ square, $3 \mathrm{~mm}$ thickness) were immersed in distilled water for $48 \mathrm{~h}$ and the films were removed and weighed to an accuracy of $0.0001 \mathrm{~g}$.

\section{Mechanical Properties}

The mechanical properties such as tensile, flexural, impact and hardness were measured. The tensile properties were determined as per ASTM D 3039 for specimens of the width of $25 \mathrm{~mm}$, length of 200 $\mathrm{mm}$, and thickness of $3 \mathrm{~mm}$. The specimens having dimensions $3 \mathrm{~mm}$ in depth, $10 \mathrm{~mm}$ in width, and 100 $\mathrm{mm}$ in length was used for flexural strength measurement at $5 \mathrm{~mm} \mathrm{~min}^{-1}$ cross-head speed using HTEseries-H50 K-S Model (Hounsfield test equipment Ltd, UK) as per ASTM D 790. The samples of nanocomposites were analyzed as per ASTM D 256-88 to determine the impact strength. A DurometerType D and Hardness was calculated using the specimens of $3 \mathrm{~mm}$ thickness as per ASTM D 2240.

\section{Dielectric Constant}

The dielectric constant behavior was studied using an impedance analyzer (PSM1735 NumetriQ) at room temperature (RT). The polymer samples were made in the form of a film ( $1 \mathrm{~mm}$ thickness $\times 13 \mathrm{~mm}$ dia. $)$, by applying a pressure of 3.5 tons for impedance measurements using platinum (Pt) electrode in the frequency range at $1 \mathrm{MHz}$. The dielectric constant of the samples was determined using $\varepsilon^{\prime}$ as the standard relations.

\section{Morphological Properties}

The SEM of the fractured surfaces was carried out using a JEOL JSM Model 6360 microscope. The specimens were coated with platinum and were exposed to an accelerating voltage of $20 \mathrm{kV}$. The hybrid film morphology was also studied using SEM.

\section{FT-IR Spectral Analysis of BMIDPE}

\section{RESULTS AND DISCUSSION}

The FT-IR spectrum (Fig.-1)of flexible linkage aliphatic bismaleimide show a strong absorption corresponding to imide ring around $1,720 \mathrm{~cm}^{-1}$ due to the asymmetric and symmetric $\mathrm{C}=\mathrm{O}$ stretching vibration. $\mathrm{C}-\mathrm{N}-\mathrm{C}$ stretching vibration of imide ring is also observed as bands around $1,350 \mathrm{~cm}^{-1}$ and the band $\mathrm{CH}_{3}$ group showed a symmetric stretching around $2866 \mathrm{~cm}^{-1}$. Further, the C-O-C bond (alkoxy) shows a strong absorption band $d^{44,45}$ at $1,030 \mathrm{~cm}^{-1}$. The appearance of new absorption peaks at $2953 \mathrm{~cm}^{-1}$ (C-H stretching) and $1457 \mathrm{~cm}^{-1}$ (C-H bending) also specified the formation of bismaleimide ring ${ }^{41}$.

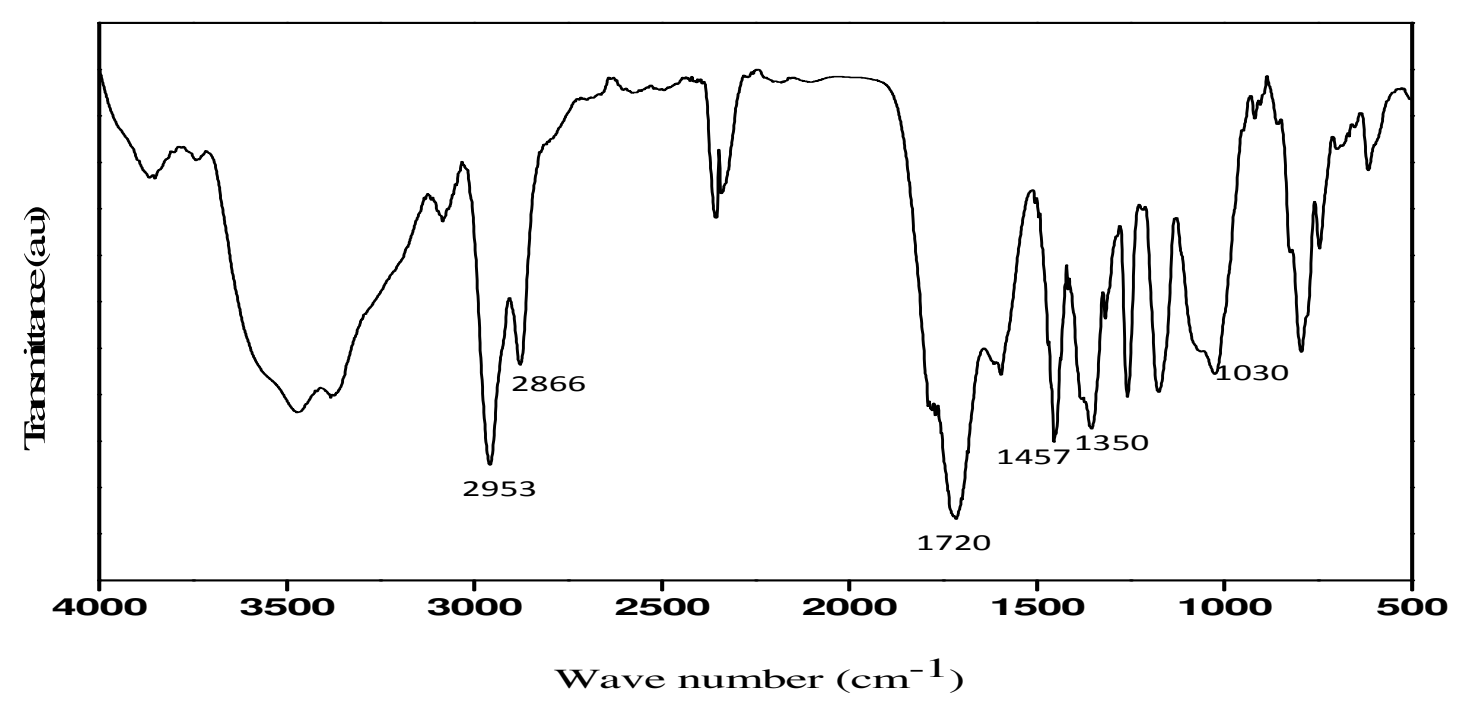

Fig.-1: FT-IR Spectrum of Polyetherdiamine based Bismaleimide 


\section{FT-IR Spectral Analyses of Nanocomposites}

The FT-IR spectral data of BMIDPE toughened DGEBA epoxy matrix resins and MWCNT-incorporated BMIDPE blended DGEBA epoxy matrix resins are listed as shown in Fig.-2.

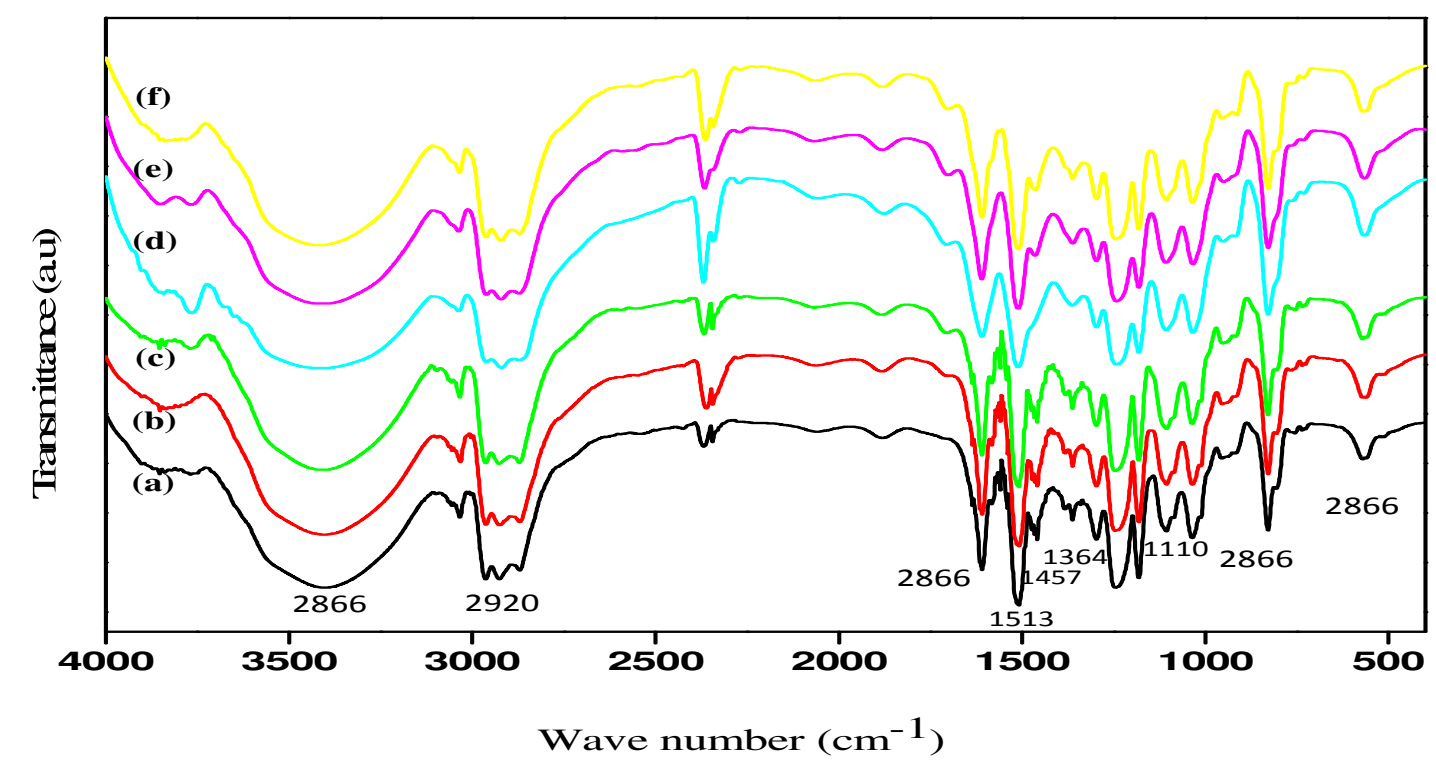

Fig.-2: FT-IR Spectra of the Neat BMI/DGEBA and BMI/DGEBA/MWCNT Nanocomposites

The ring opening reaction of epoxy of was ascertained by the disappearance of an absorption peak corresponding to oxirane group of the epoxy matrix at $914 \mathrm{~cm}^{-1}$. The thermal imidization was then confirmed by an absorption band at $1364 \mathrm{~cm}^{-1}$ (-C-N in the imide groups). The peak was observed at 1110 $\mathrm{cm}^{-1}$ corresponding to $\mathrm{CH}_{2}$ wagging of imide rings. There, an anti-symmetrical deformation of $\mathrm{CH}_{3}$ was observed at $1457 \mathrm{~cm}^{-1}$. The presence of aliphatic C-H group was confirmed by a peak around $2920 \mathrm{~cm}^{-1}$ ${ }^{47,50}$. The other important peaks are $1513 \mathrm{~cm}^{-1}$ which is because of the C-N-C stretching respectively ${ }^{50}$. The completion of curing of the BMI chains was indicated from the absorption band in the range of 1000$500 \mathrm{~cm}^{-1}$ with a reduced number of peaks ${ }^{41-42}$. Upon the addition of MWCNT to DGEBA, the formation of MWCNT/DGEBA is confirmed by the disappearance of the peak at $1610 \mathrm{~cm}^{-1}$ due to the amide groups. These observed absorption bands revealed that MWCNT was successfully incorporated into DGEBA matrices and coincided very well with the reported earlier ${ }^{50}$ data.

\section{Thermal Properties}

\section{Differential Scanning Calorimetric Analysis}

The glass transition temperatures $\left(T_{g}\right)$ of the conventional DGEBA epoxy system, BMIDPE/DGEBA epoxy and MWCNT/BMIDPE/DGEBA epoxy systems were determined from DSC analysis and are listed in Table 1 and Fig.-3.The values of $T_{g}$ were reduced with the rise in the concentration of BMIDPE content into DGEBA epoxy systems, as shown in Table 1.The BMI toughened DGEBA displays $T_{g}$ around 145 ${ }^{\circ} \mathrm{C}$ than those of neat epoxy $165-168^{\circ} \mathrm{C}$. On adding $5 \%, 10 \%$, and $15 \%$ of BMI into the epoxy matrix, $T_{g}$ values are $185.4^{\circ} \mathrm{C}, 146.4^{\circ} \mathrm{C}$, and $134.8^{\circ} \mathrm{C}$, respectively. The presence of the chain extended and aliphatic flexible units decreased the effective crosslink density, which in turn reduces the curing temperature by accelerating the reaction rate. The segmental mobility of molecules established by extra free volume in the matrix system leads to a drop in the values of $T_{g}$. This kind of an intercross linking network formation between BMIDPE and epoxy was ascertained from the single $T_{g}{ }^{34,41}$.

The incorporation of MWCNT into BMIDPE-toughened DGEBA epoxy matrices also increased the $T_{g}$ value. For example, the incorporation of MWCNT (1.5 wt \%) into 10\% BMIDPE-blended DGEBA epoxy resin matrix possess the $T_{g}$ value of $254.8^{\circ} \mathrm{C}$ and that of the BMIDPE - blended DGEBA epoxy resin system displayed $146.4^{\circ} \mathrm{C}$ (Table-1). It is suggested that the increase in $T_{g}$ value of MWCNT-filled BMIDPE-toughened DGEBA epoxy nanocomposites may probably due to the reinforcement of the 
MWCNT with the crosslink density and thus the access of the molecules of epoxy resin DGEBA is hindered, which results in a higher degree of cross-linking and as a consequence a higher $T_{g}$ value ${ }^{46-48}$.

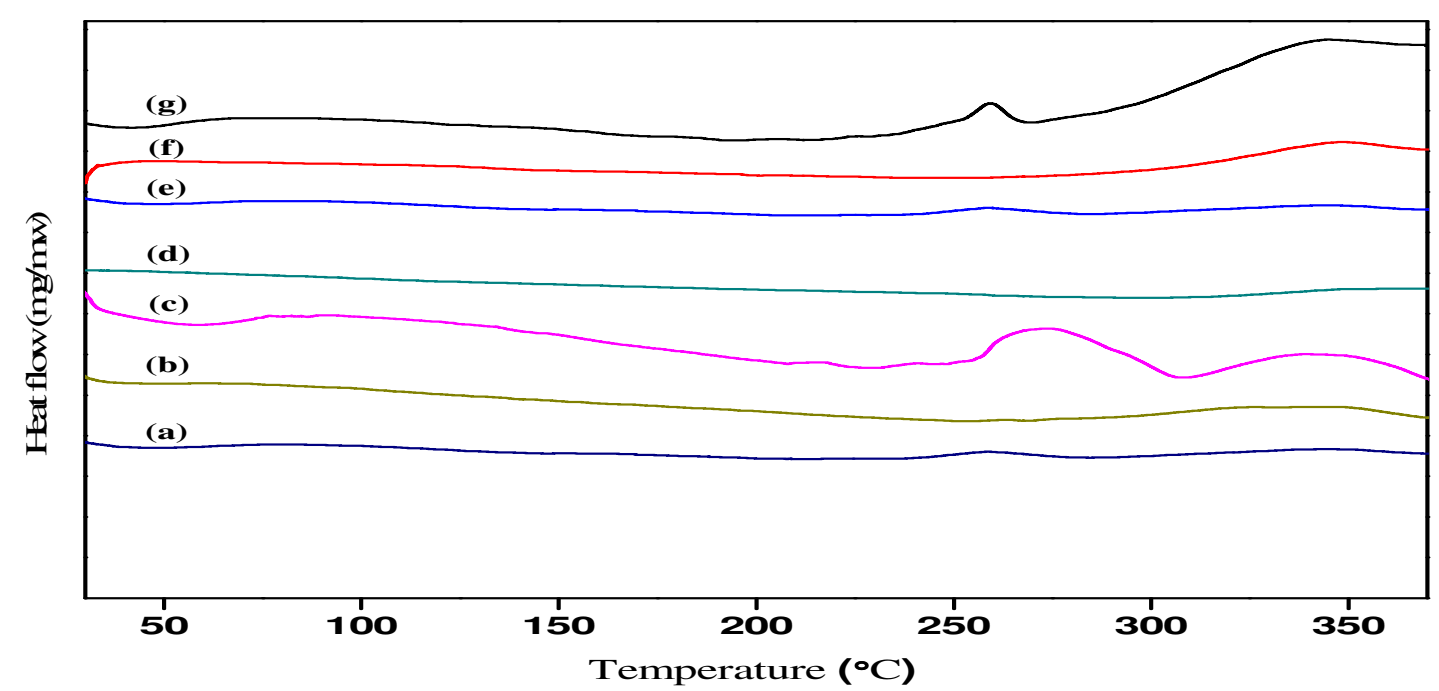

Fig.-3: DSC Thermogram of the Neat BMI/DGEBA and BMI/DGEBA/MWCNT Nanocomposites

Table-1: Thermal and Dielectric Data of the Neat BMI/DGEBA and BMI/DGEBA/MWCNT Nanocomposites

\begin{tabular}{c|c|c|c|c|c}
\hline \multirow{2}{*}{ Systems } & $\begin{array}{c}\text { Percentage } \\
\text { Composition } \\
(\mathrm{Wt} \%)\end{array}$ & $\begin{array}{c}\text { The temperature } \\
\text { for Weight Loss } \\
\text { @ } 50 \%\left({ }^{\circ} \mathrm{C}\right)\end{array}$ & $\begin{array}{c}\text { Glass } \\
\text { Transition } \\
\left({ }^{\circ} \mathrm{C}\right)\end{array}$ & $\begin{array}{c}\text { Char } \\
\text { Yield } \\
\%\end{array}$ & $\begin{array}{c}\text { Dielectric } \\
\text { Constant } \\
\left(\varepsilon^{\prime}\right)\end{array}$ \\
\hline \multirow{4}{*}{$\begin{array}{c}\text { DGEBA/BMI } \\
\text { Composite }\end{array}$} & $100 / 00 / 00$ & 370 & 190.2 & 0 & 3.5 \\
\cline { 2 - 6 } & $100 / 05 / 00$ & 425 & 185.4 & 0.9 & 3.8 \\
\cline { 2 - 6 } & $100 / 10 / 00$ & 465 & 146.4 & 1.5 & 4 \\
\hline \multirow{2}{*}{$\begin{array}{c}100 / 15 / 00 \\
\text { DGEBA/BMI/ MWCNT }\end{array}$ Composite } & $100 / 10 / 0.5$ & 438 & 134.8 & 2.1 & 4.3 \\
\cline { 2 - 6 } & $100 / 10 / 1.5$ & 476 & 237.5 & 17 & 5.2 \\
\hline
\end{tabular}

\section{Thermogravimetric Analysis}

The thermal stability and degradation temperature of BMIDPE into DGEBA epoxy matrices were augmented as the concentration of BMIDPE were increased. The cross-linked structure and the entangled network of BMIDPE/DGEBA epoxy resin systems which delayed the degradation temperature caused by the BMIDPE moiety ${ }^{48}$. Furthermore, the incorporation of COOH-MWCNTs into epoxy matrices boosted thermal stability since nanocomposites act as a heat-proofing and mass transport barrier to the volatile products generated during decomposition. With the increasing percentage concentration of MWCNT, the degradation temperatures of MWCNT incorporated BMIDPE/DGEBA systems were increased. The MWCNT-filled BMIDPE/DGEBA epoxy resin systems exhibited the superior thermal stability and greater char yield than that of neat BMIDPE/DGEBA epoxy systems (Fig.-4).

It was also found out that the MWCNT-filled BMIDPE-toughened DGEBA matrix nanocomposites which are more thermally stable than those of the BMIDPE-toughened DGEBA nanocomposites because of their hindering effect of vastly crosslinked structure in the matrix. However, the addition of $\mathrm{COOH}-$ MWCNTs slightly improves the thermal stability of DGEBA/MWCNT system ${ }^{47}$ observed from Fig.-5. 
RASĀYAN J. Chem.

Vol. 12 | No. 1 |168 - 183| January - March | 2019

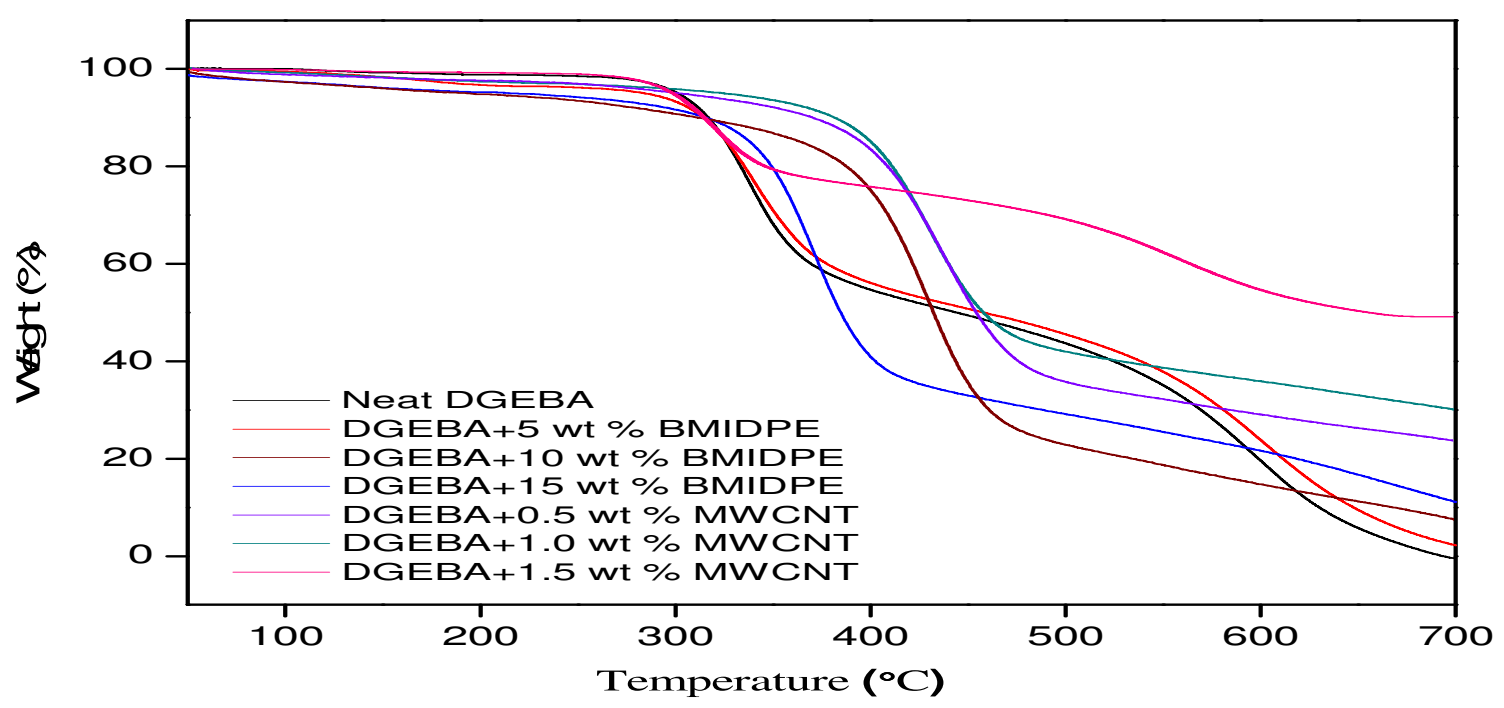

Fig.-4: TGA Thermogram of the Neat BMI/DGEBA and BMI/DGEBA/MWCNT Nanocomposites
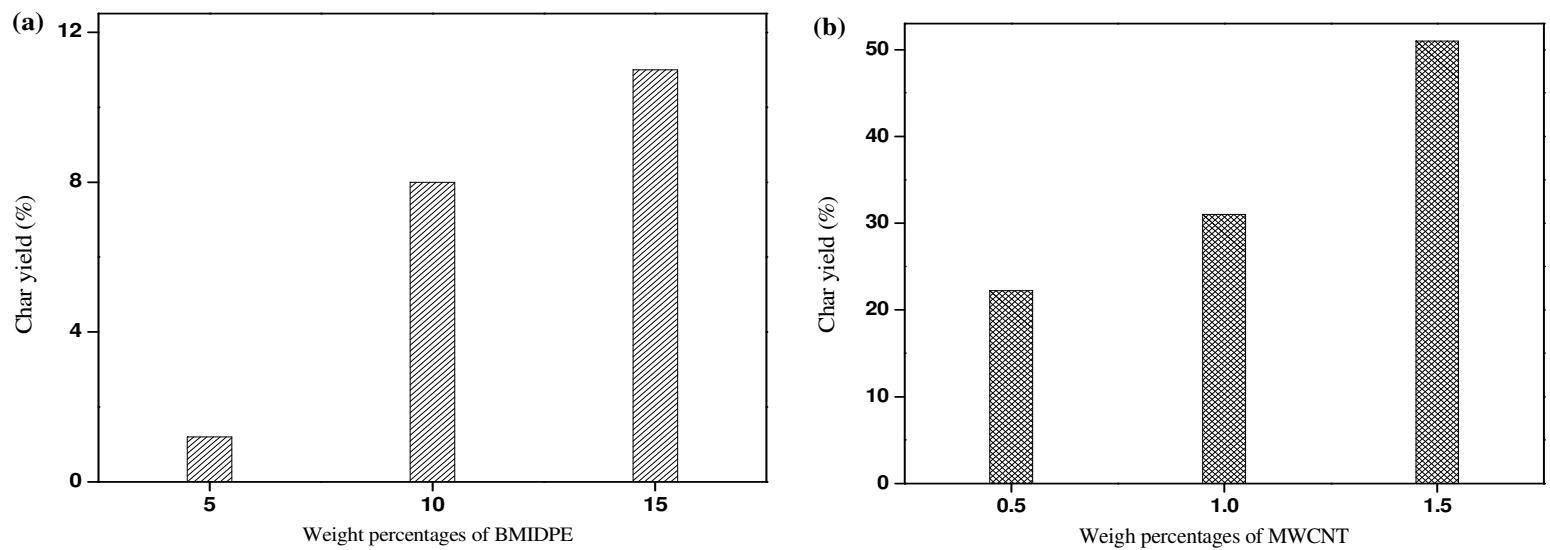

Fig.-5: Char Yield Comparison of the (a) Neat BMI/DGEBA and (b) BMI/DGEBA/MWCNT Nanocomposites

\section{X-Ray Diffraction Analysis}

The XRD behavior of the BMIDPE toughened DGEBA resin systems and BMIDPE toughened DGEBA/MWCNT nanocomposites are shown in Fig.-6. The diffractogram of BMIDPE/DGEBA matrix gives a broad peak showing that the epoxy is blended with BMIDPE which assigned the structure of the epoxy systems to amorphous. On adding MWCNTs into the BMIDPE/DGEBA matrix, this peak respective to $2 \theta=18.5^{\circ}$ shifted towards slightly higher value in turn clearly shows that the incorporation of MWCNTs into epoxy matrix refines the microstructure of the composites by the means of interfacial interaction between the MWCNTs and epoxy matrix.

From the diffractograms, it can be shown that the MWCNT has well reacted with the BMI/DGEBA system, thus results in a broad peak. The disappearance of the small sharp peak has also confirmed that the formed MWCNT reinforced DGEBA nanocomposites are amorphous and highly exfoliated in their end form also homogeneous dispersion of MWCNT.

\section{Water Absorption Behavior}

The BMI incorporation into epoxy resin matrix resulted in lower water uptake property according to their concentration (Fig.-7a and b). This is hence because of the creation of intercross linking structure formed between inherent water repellent bismaleimide and the epoxy resin matrix. The reduction in water uptake percentage of the BMI blended epoxy resin matrix is due to the characteristic water repellent nature of BMI networks ${ }^{48}$. 
RASĀYAN J. Chem.

Vol. 12 | No. 1 |168 - 183| January - March | 2019

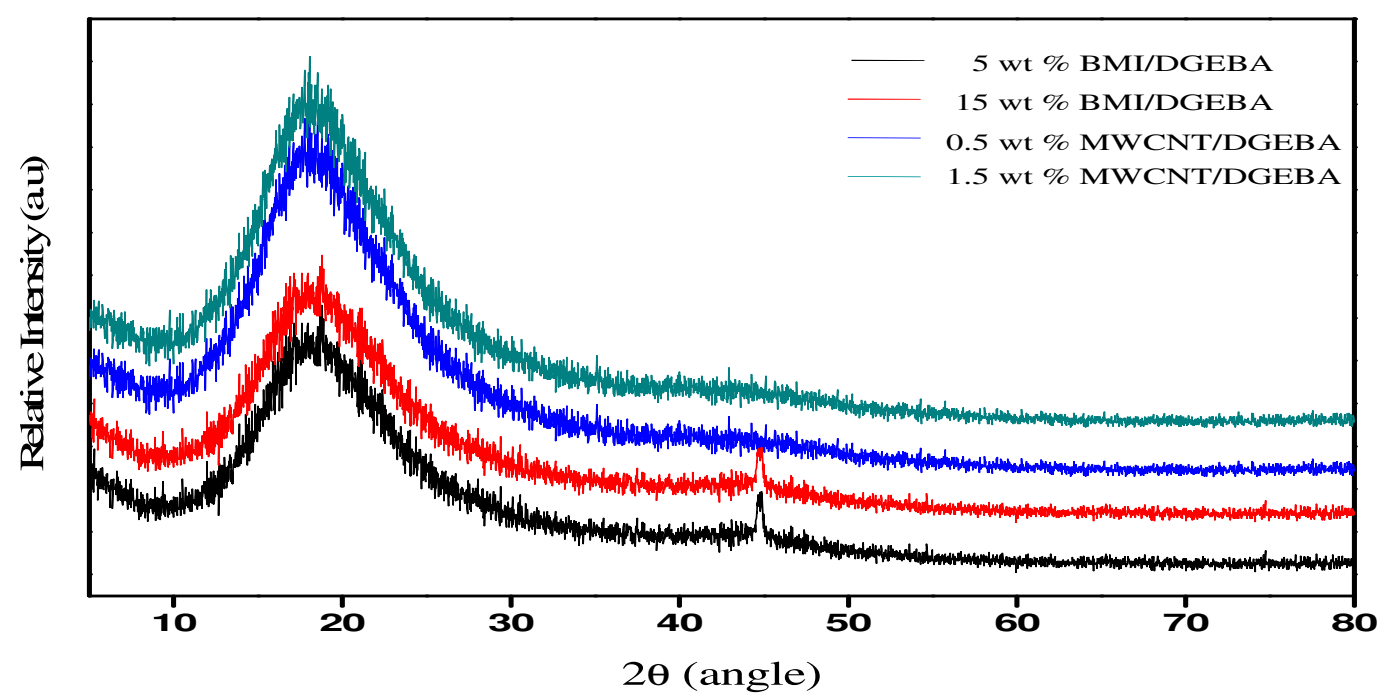

Fig.- 6: XRD Pattern of the (a) Neat BMI/DGEBA and (b) BMI/DGEBA/MWCNT Nanocomposites
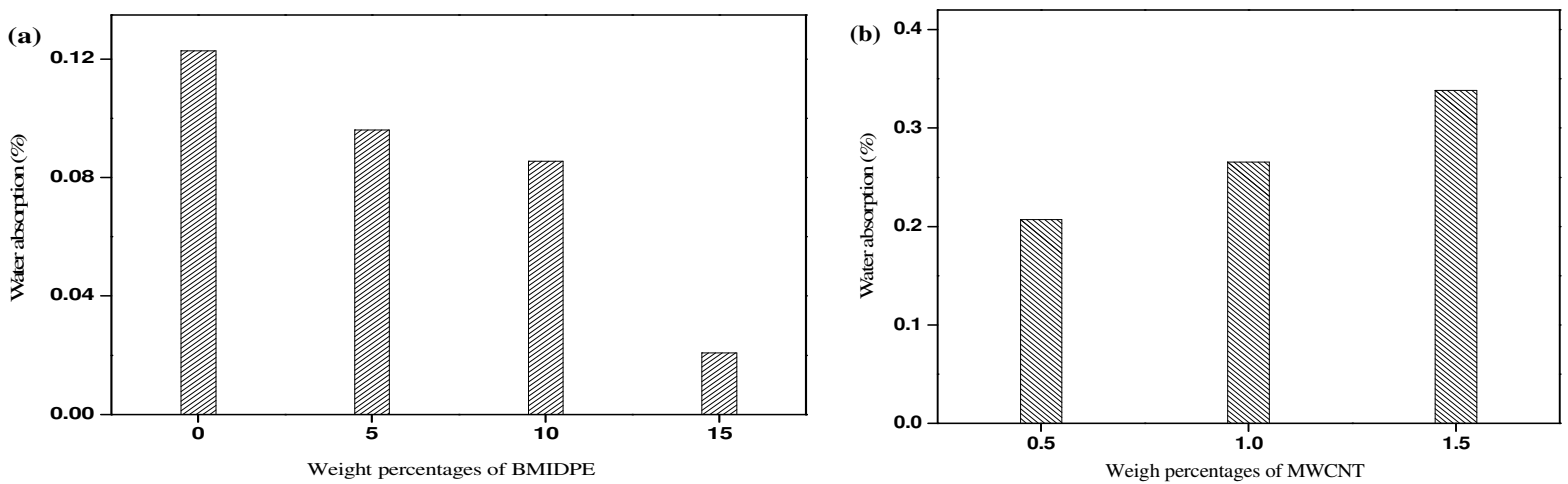

Fig.-7: Water Absorption Behaviour of the (a) Neat BMI/DGEBA and (b) BMI/DGEBA/MWCNT Nanocomposites

Hence, it is indicated that the BMI offers a significant role in enhancing the resistance to water absorption of nanocomposites ${ }^{23}$. However, the reinforcement of $0.5,1.0$ and $1.5 \mathrm{wt} \%$ of MWCNT into $10 \%$ BMIDPE-DGEBA epoxy matrix increased the water absorbing properties. This is supported by the presence of hydroxyl groups in the MWCNT networks.

\section{Mechanical Properties}

Tensile Behavior

The tensile properties of neat DGEBA, BMIDPE/DGEBA epoxy systems and MWCNT filled DGEBA epoxy resin systems are presented in Table-1 and Fig.-8a and d. The inclusion of BMIDPE into DGEBA epoxy matrices suppressed the tensile behavior with 5,10 and 15\% BMIDPE into the DGEBA epoxy matrix comparing with those of unmodified epoxy matrices.

Table-2: Mechanical Properties of the Neat BMI/DGEBA and BMI/DGEBA/MWCNT Nanocomposites

\begin{tabular}{c|c|c|c|c|c|c|c|c}
\hline Sample & $\begin{array}{c}\text { Percentage } \\
\text { Composition }\end{array}$ & $\begin{array}{c}\text { Tensile } \\
\text { Strenth } \\
(\mathrm{MPa})\end{array}$ & $\begin{array}{c}\text { Tensile } \\
\text { Modulus } \\
(\mathrm{MPa})\end{array}$ & $\begin{array}{c}\text { Flexural } \\
\text { Strength } \\
(\mathrm{MPa})\end{array}$ & $\begin{array}{c}\text { Flexural } \\
\text { Modulus } \\
(\mathrm{MPa})\end{array}$ & $\begin{array}{c}\text { Hardness } \\
(\mathrm{MPa})\end{array}$ & $\begin{array}{c}\text { Izod- } \\
\text { unnotched } \\
\text { Impact } \\
\text { Strength } \\
(\mathrm{J} / \mathrm{m})\end{array}$ & $\begin{array}{c}\text { Water } \\
\text { Absorption } \\
(\%)\end{array}$ \\
\hline $\begin{array}{c}\text { DGEBA/ } \\
\text { BMI } \\
\text { systems }\end{array}$ & $100 / 00 / 00$ & 61.20 & 2721 & 107.0 & 1813 & 84.3 & 101.7 & 0.1229 \\
\cline { 2 - 9 } & $100 / 05 / 00$ & 54.21 & 1910 & 32.7 & 2670 & 159.3 & 108.5 & 0.0961 \\
\hline
\end{tabular}


RASĀYAN J. Chem.

Vol. 12 | No. 1 |168 - 183| January - March | 2019

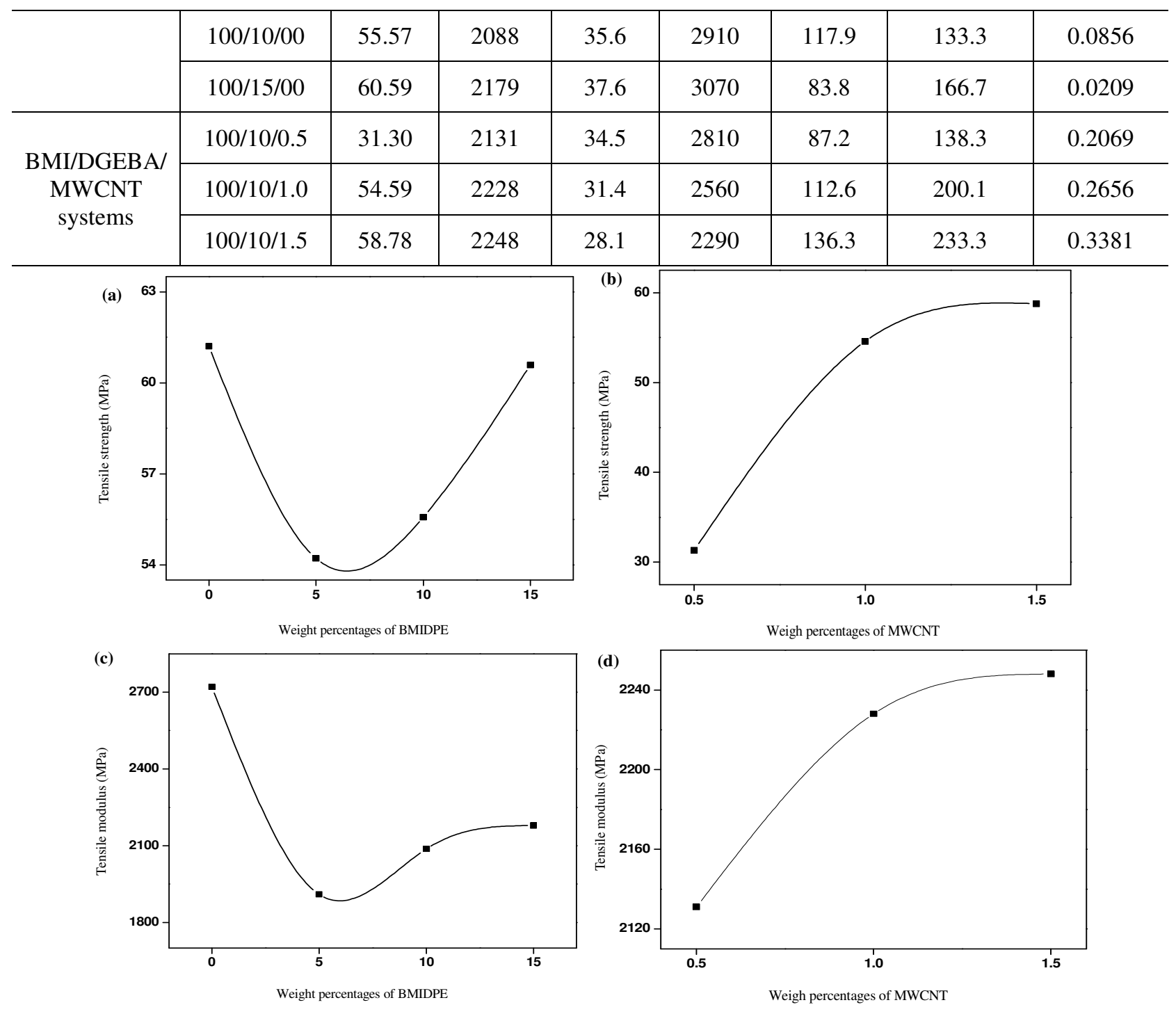

Fig.-8: Tensile Strength of the (a) Neat BMI/DGEBA and (b) BMI/DGEBA/MWCNT Nanocomposites and Tensile Modulus of (c) Neat BMI/DGEBA and (d) BMI/DGEBA/MWCNT Nanocomposites

The tensile strength of BMI-epoxy matrices are decreased with the increased BMI content whereas, it increased with increasing MWCNT content for BMIDPE-DGEBA/MWCNT nanocomposites. The introduction of $1.5 \mathrm{wt} \%$ of MWCNT into $10 \%$ BMIDPE-DGEBA epoxy resin matrix enhanced the tensile strength by $7 \%$, respectively. The increase in the compatibility between the BMI and the carbon nanotubes through the chain extending reaction of DDM has increased the tensile strength of MWCNT/BMI/DGEBA nanocomposites ${ }^{43}$.

\section{Flexural Behavior}

The Table-2 and Fig.-9a to d represent the flexural properties of neat DGEBA, BMIDPE-toughened DGEBA epoxy and MWCNT/DGEBA epoxy nanocomposites. The flexural strength of the epoxy is considerably increased with the newly introduced BMIDPE matrix in the epoxy resin as a result of the network formed between the BMIDPE and epoxy system.

The values of flexural strength according to nature and percentage incorporated bismaleimide are enhanced as witnessed as in the case of tensile strength. The rise in flexural strength is remarkably influenced by the homopolymerization of BMI and an interpenetrating network structure between the 
epoxy resin and BMI formed ${ }^{34}$. The flexural modulus of the nanocomposites was raised to an extreme amount of $70 \%$ for the modified BMI as compared to the neat BMI.

It has been hypothesized that MWCNT inhibits dissolution in the modified resin-based composite, which in turn altered the brittle or crystalline nature into a semi-crystalline or amorphous structure and thus resulted in the reduction of flexural strength of the nanocomposites.
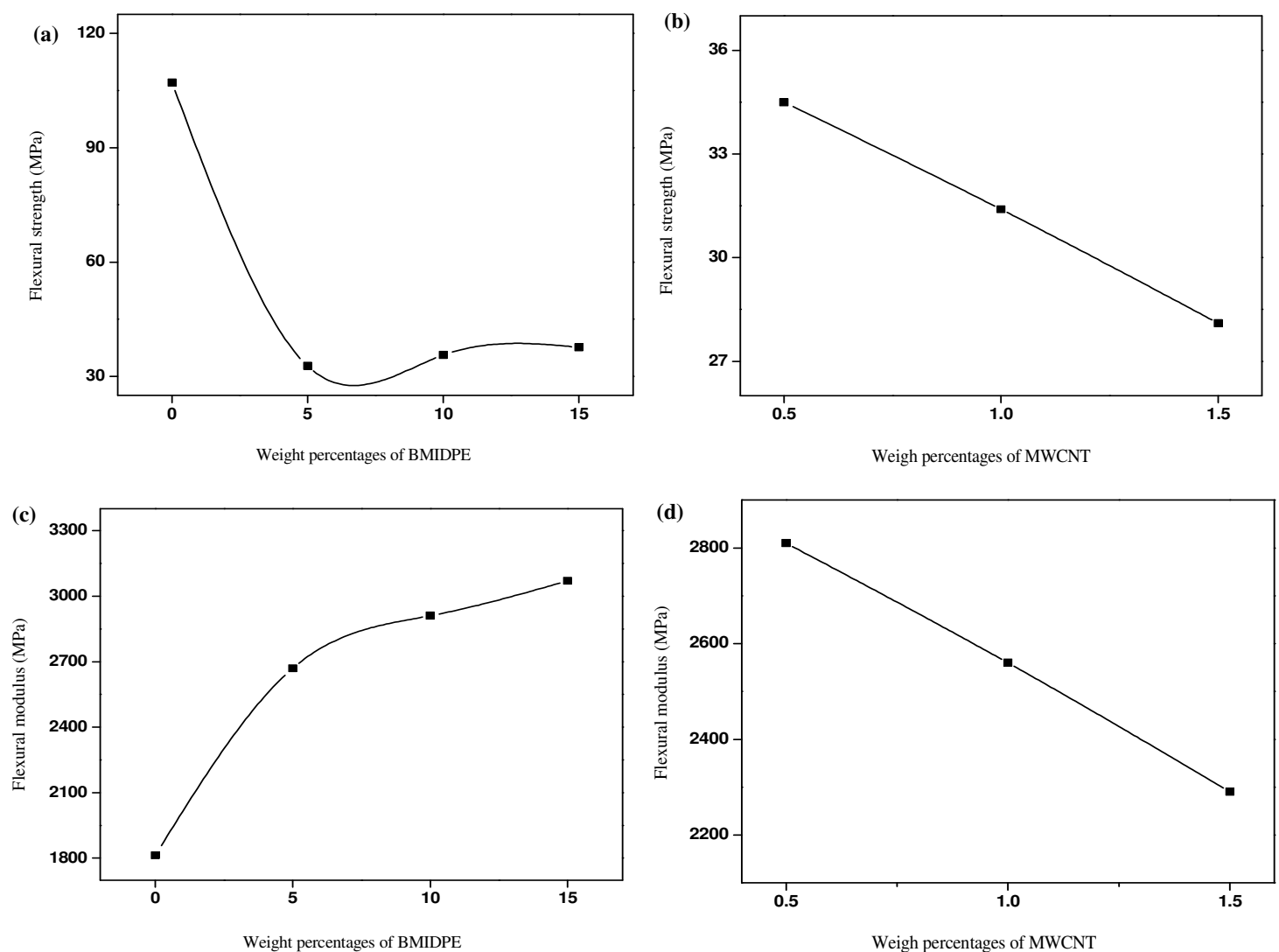

Fig.- 9: Flexural Strength of the (a) Neat BMI/DGEBA and (b) BMI/DGEBA/MWCNT Nanocomposites and Flexural Modulus of (c) Neat BMI/DGEBA and (d) BMI/DGEBA/MWCNT Nanocomposites

\section{Impact Behavior}

The impact properties of neat DGEBA, BMIDPE-toughened DGEBA epoxy and MWCNT filled DGEBA epoxy nanocomposites are presented in Table-2 and Fig.-10a and b.
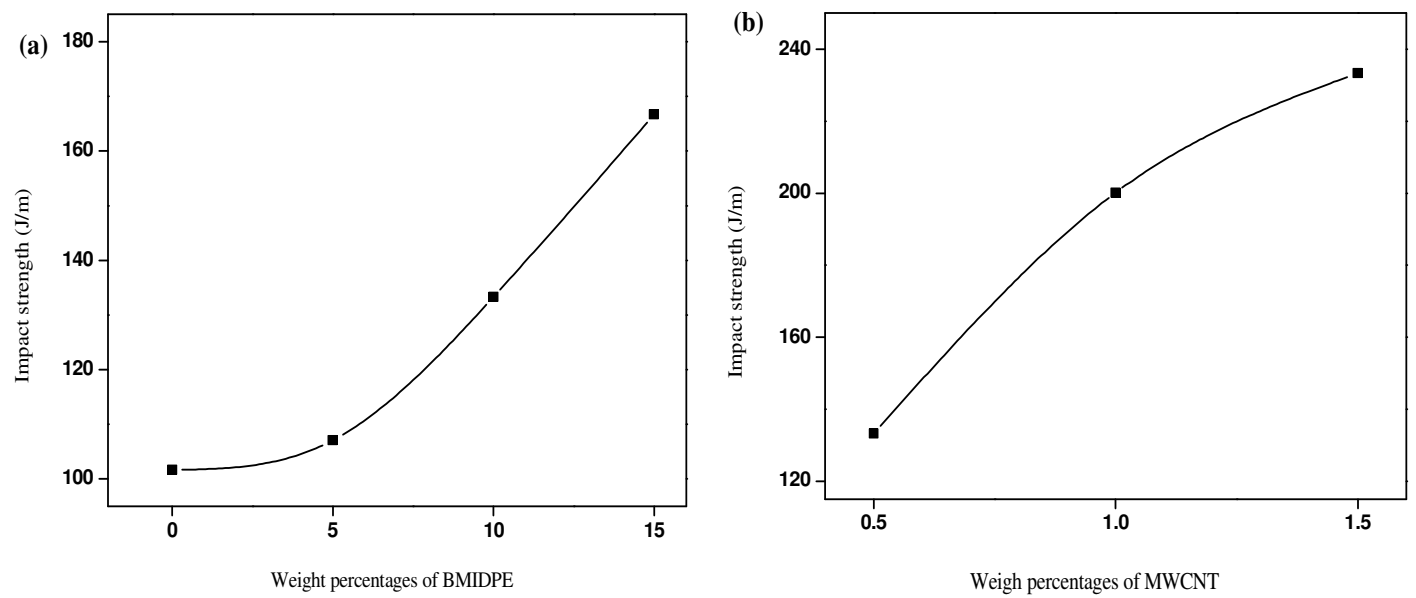

Fig.-10: Impact Strength of the (a) Neat BMI/DGEBA and (b) BMI/DGEBA/MWCNT Nanocomposites 
RASĀYAN J. Chem.

Vol. 12 | No. 1 |168 - 183| January - March | 2019

This enhancement is described as a result of the chain enlargement by the incorporation of polyether amine and the creation of the flexible structure within the matrix system. Furthermore, the existence of ether linking in the polyether amine structure is also accountable for the better improvement of the impact strength owing to its unrestricted molecular movement. But, the magnitudes of impacts of BMI/epoxy are superior to unmodified epoxy matrix. ${ }^{34,41}$

The introduction of $0.5,1.0$ and $1.5 \mathrm{wt} \%$ of MWCNT into10 \% BMIDPE-DGEBA epoxy resin matrix elevated the impact strength by 3,50 \& $75 \%$ correspondingly. This was ascribed to the flexibility exerted due to the higher stiffness and strength of the MWCNT, which act as tiny and arbitrarily dispersed tubes. On comparing the values of impacts of the BMIDPE/DGEBA system with the BMIDPE/DGEBA epoxy based MWCNT nanocomposites, they displayed higher values than that of BMIDPE caused by the existence of higher cross linking density. This may be elucidated by the improved flexibility of the network of BMIDPE/DGEBA than that of BMIDPE/DGEBA. The extended chain develops toughness and processibility of BMI because of the expansion of the chain length that has a tendency to increase the toughness of the BMI system. On the other hand, the crosslinked structure through Michael-addition reaction is formed by the reaction of bis-nucleophilic species with the BMI system. According to the percentage content of BMI, the fusion of BMI into epoxy resin matrix increases the toughness, owing to the suppressed crosslinked structure density and a larger percentage of flexible ether network ${ }^{50}$.

\section{Hardness}

Comparing with DGEBA resin, a significant increment of hardness is obtained for BMI/DGEBA nanocomposites (Fig.-11a and b).It is seen that the inclusion of BMI into epoxy matrix reduces the hardness to remarkable value. The hardness of the neat epoxy system is observed as $84 \mathrm{MPa}$, whereas the $5 \%, 10 \%$ and $15 \%$ BMI modified epoxy show 159.3, 117.9 and $83.8 \mathrm{MPa}$.
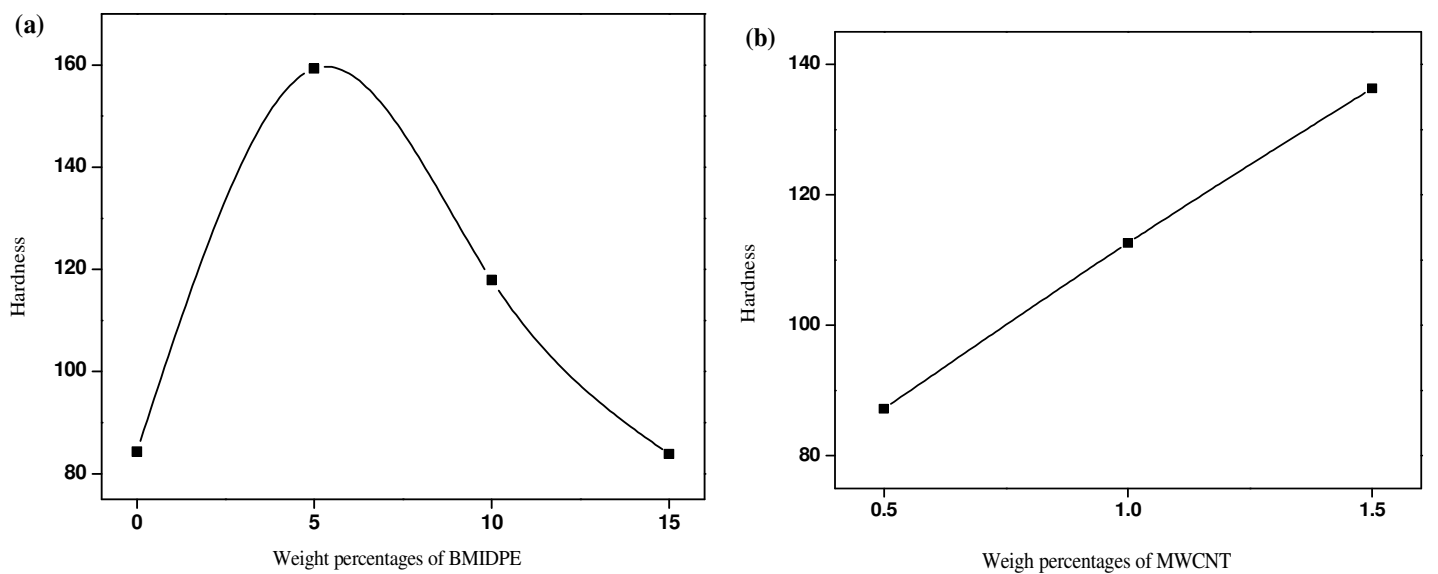

Fig.-11: Hardness of the (a) Neat BMI/DGEBA and (b) BMI/DGEBA/MWCNT Nanocomposites

This may be ascribed to the inherent flexible molecular structure of BMI and the inclusion of flexible linkage between BMI and the epoxy resin matrix. Furthermore, this existence of homopolymerization of BMI and the establishment of intercross linking structure between the BMI and epoxy resin matrix are both remarkably responsible for the hardness. Epoxy/MWCNT nanocomposites resulted in the hardness value of 136.3 MPa which is $16 \%$ more that of BMIDPE/epoxy sample. The reinforcement of nanotube and its derived high strength may effect in forming a network structure that expands the hardness of the composites.

\section{Dielectric Properties}

The dielectric constant values of the BMIDPE-toughened DGEBA/MWCNT epoxy nanocomposites were higher than neat epoxy (Table-1 and Fig.-12a and b). This increment was due to interfacial polarization exerted in MWCNTs. The low-frequency dielectric constant values of the composites have substantially influenced by the polymer flexibility. Especially, the existence of dipole nature in the polymer resin 
matrix and their movement strongly impact the dielectric constant. The amount of the dielectric loss also improved with the growing polarity of the polymer component. ${ }^{51,53}$
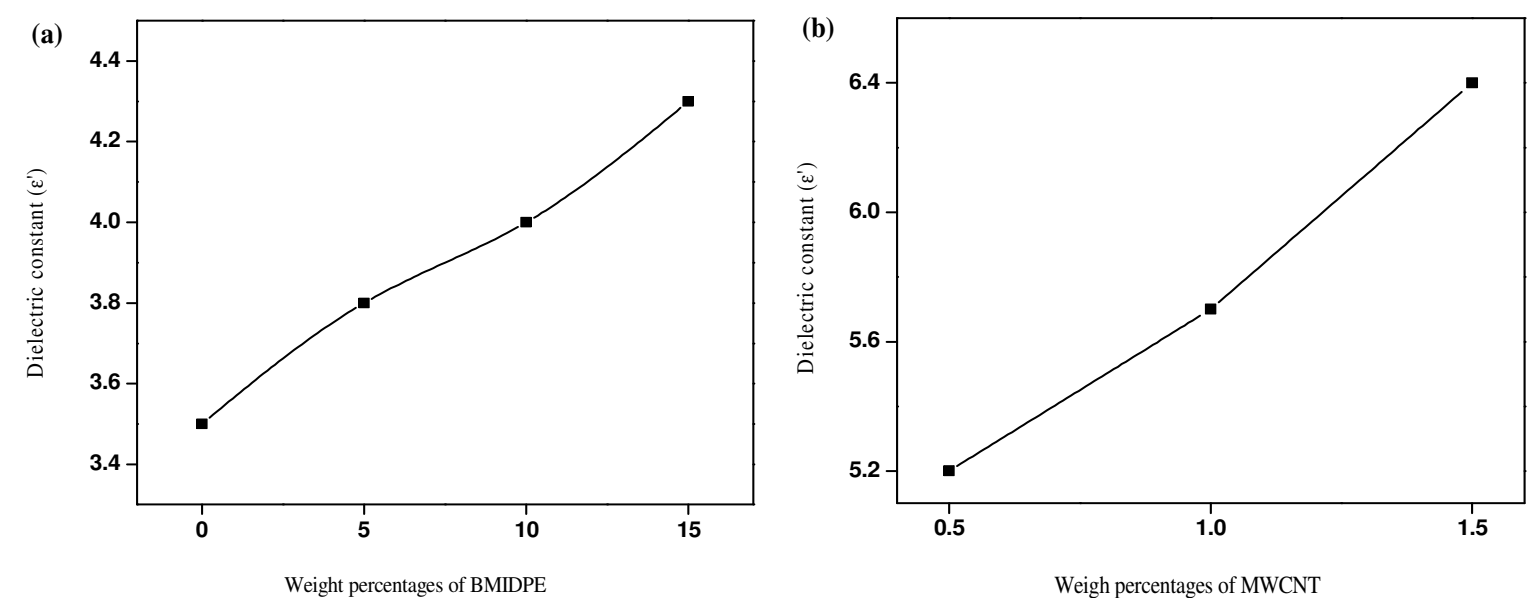

Fig.-12: Dielectric Behaviour of the (a) Neat BMI/DGEBA and (b) BMI/DGEBA/MWCNT Nanocomposites

\section{Morphology}

The morphological behavior of the epoxy resin nanocomposites was studied by SEM and the rough surfaces of the neat DGEBA epoxy and MWCNT/epoxy resin nanocomposites are shown in Fig.-13. The neat BMIDPE-toughened DGEBA epoxy systems display a relatively fine fracture surface even at the upper magnification ${ }^{34,41,52}$ from Fig.-13a and b.
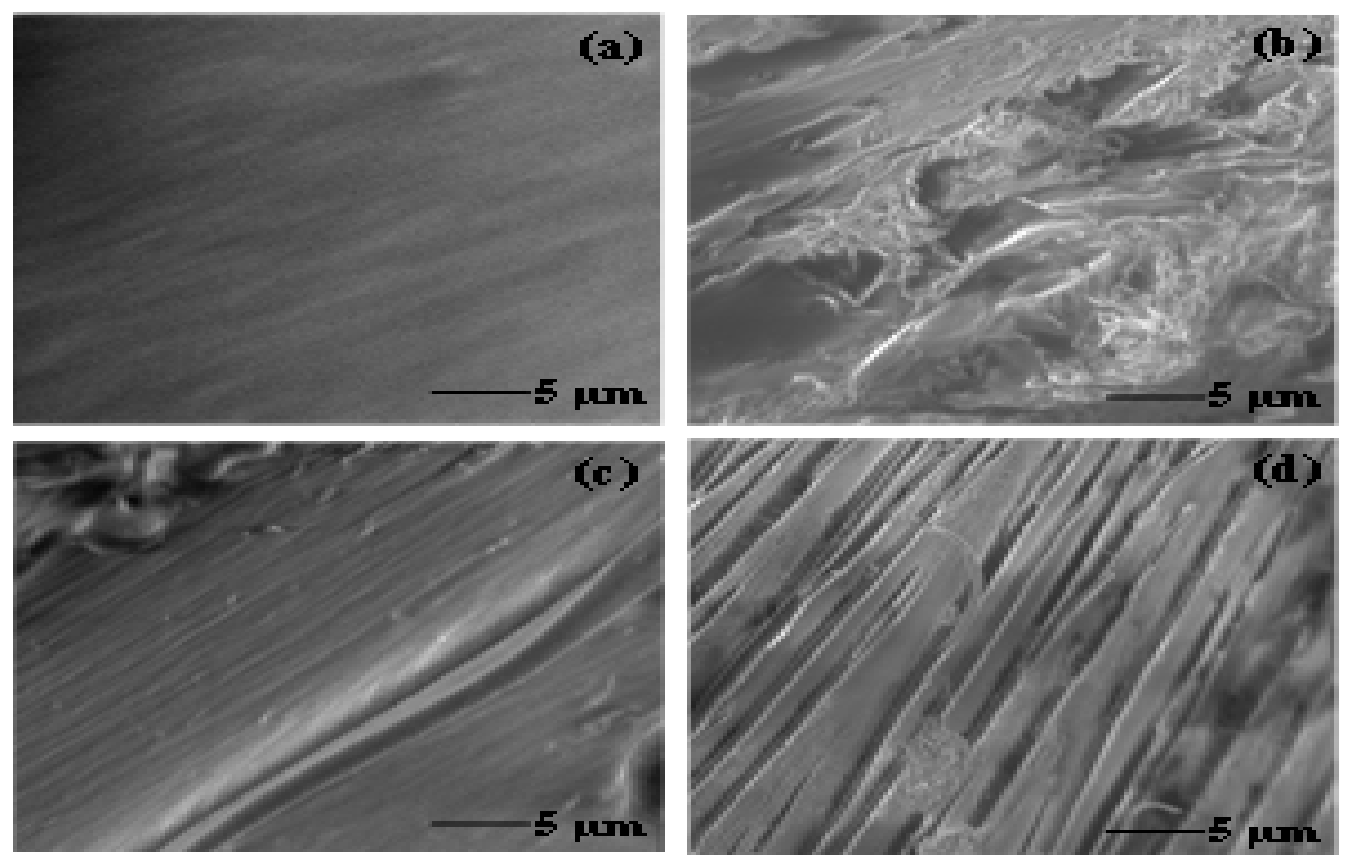

Fig.-13: SEM Images of the (a) Neat BMI/DGEBA and (b) BMI/DGEBA/MWCNT Nanocomposites

The rough surfaces of the nanocomposites show noticeably no apparent fractographic separation between the MWCNT and epoxy resins was noticed. The rough surfaces of the nanocomposites are coarse with the MWCNTs added into the epoxy system as seen Fig.-13c and d. In addition, the transparent and homogeneous morphology of MWCNT clearly indicates the effective miscibility of MWCNT in the epoxy system. The miscibility could be arisen due to the covalent bond formation between the acidmodified MWCNT and the epoxy matrix and led to the development of nanocomposites with exfoliated structures ${ }^{43}$. 
RASĀYAN J. Chem.

Vol. 12 | No. 1 |168 - 183| January - March | 2019

\section{CONCLUSION}

A novel bismaleimide toughened multi-wall carbon nanotube reinforced epoxy nanocomposites has been structurally designed, developed and characterized. The reinforcement efficiency of MWCNTs filler in the epoxy matrix was assessed along with the thermal stability and $T_{g}$. The tensile strength of the nanocomposite was improved to $7 \%$ with merely $1.5 \mathrm{wt} \%$ loading of acid modified carbon nanotubes than the neat BMI/DGEBA matrix. The developed nanocomposites showed substantial changes in Young's modulus than that of neat epoxy. This substantial enhancement recommended an efficient way to recognize an industrial application of nanotubes reinforcing epoxy nanocomposite. With only $1.5 \mathrm{wt} \%$ loading, the flexural modulus of MWCNT/epoxy composite was drastically augmented by $70 \%$ whereas the flexural modulus of the neat epoxy matrix was only improved by $32 \%$. The reduction in water uptake properties for the BMI/epoxy matrix is due to the intrinsic water repellent nature of bismaleimide linkages which ascertain water repellent properties of the composites. The incorporation efficiency of MWCNTs fillers in the epoxy matrix was assessed along with the electrical and mechanical properties. In addition, MWCNT/epoxy nanocomposites resulted in better-enhanced impact strength and hardness representing that there is effective load transfer between the polymer matrix and the reinforced nanotube at the nanolevel. The dielectric constant values of the resulted nanocomposites were enhanced by means of increased weight percentages of MWCNT into the epoxy matrix. SEM microphotographs revealed that MWCNT was thoroughly impregnated in the polymer matrix with the presence of the chemical bonding between MWCNT and the epoxy matrix. Such a unique combination of thermal, mechanical and dielectric properties opens the door for developing nanocomposites eventually with multi-functionalities.

\section{ACKNOWLEDGMENT}

The author acknowledges Dr. R. Jayavel, Director, Centre for Nanoscience and Nanotechnology, Anna University, Chennai, India for providing DSC and SEM analytical facility. The author thanks Mr. K. Rajakumar, Department of Chemical Engineering and Mr. S. Senthilram, Department of Textile Technology, Anna University, Chennai.

\section{REFERENCES}

1. S. Iijima, Nature, 354, 56 (1991), DOI: $10.1038 / 354056 \mathrm{a} 0$

2. N. H. Tai, M. K. Yeh and J. H. Liu, Carbon, 42, 2774 (2004), DOI: 10.1016/j.carbon.2004.06.002

3. T. Ogasawara, Y. Ishida, T. Ishikawa and R. Yokota, Compos. A Appl. Sci. Manu., 35, 67 (2004), DOI: $10.1016 /$ j.compositesa.2003.09.003

4. F. H. Gojny, M. H. G. Wichmann, U. Köpke, B. Fiedler, K. Schulte, Compos. Sci. Technol., 64, 2363 (2004), DOI: 10.1016/j.compscitech.2005.04.021

5. C. Liu, Y. Y. Fan, M. Liu, H. T. Cong, H. M. Cheng and M. S. Dresselhaus, Science, 286 (5442), 1127 (1999), DOI: $10.1126 /$ science.286.5442.1127

6. H. Sugie, M. Tanemura, V. Filip, K. Iwata, K. Takahashi and F. Okuyama, Applied Physics Lett., 78, 2578 (2001), DOI: 10.1063/1.1367278

7. E. Frackowiak and F. Beguin, Carbon, 40, 1775 (2002), DOI: 10.1016/S0008-6223(02)00045-3

8. J. Kong, N. R. Franklin, C. Zhou, M. G. Chapline, S. Peng, K. Cho and H. Dai, Science, 287(5453), 622 (2000), DOI: $10.1126 /$ science.287.5453.622

9. H. J. Dai, J. H. Hafner, A. G. Rinzler, D. T. Colbert and R. E. Smalley, Nature, 384, 147 (1996), DOI: $10.1038 / 384147 \mathrm{a} 0$

10. R. G. Villoria, A. Miravete, J. Cuartero, A. Chiminelli and N. Tolosana, Compos.Part:B Eng., 37, 273 (2006), DOI: 10.1016/j.compositesb.2006.01.002

11. S. J. Park, H. J. Jeong and C. Nah, Mater. Sci. Eng. A., 385, 13(2004), DOI: 10.1016/j.msea.2004.03.041

12. F. H. Gojny, J. Nastalczyk, Z. Roslaniec and K. Schulte, Chem. Phy. Lett., 370, 820(2003), DOI: 10.1016/S0009-2614(03)00187-8

13. P. Bartlet, J. P. Pascault and H. Sautereau, J. Appl. Polym. Sci., 30,2955 (1985), DOI: 10.1002/app.1985.070300719

14. A. Fumihiko, I. Mari, D. Nobuyoshi, K. Yoshio, S. Norifumi and M. Kenji, J. Appl. Polym. Sci., 69, 1737 (1998), DOI: 10.1002/(SICI)1097-4628(19980829) 
RASĀYAN J. Chem.

Vol. 12 | No. 1 |168 - 183| January - March | 2019

15. J. B. Donnet, Compos. Sci. Technol., 63, 1085 (2003), DOI: 10.1016/S0266-3538(03)00028-9

16. R. Bagheri and R. A. Pearson, Polymer, 41, 269 (2000), DOI: 10.1016/S0032-3861(99)00126-3

17. S. He, K. Shi, J. Bai, Z. Zhang, L. Li, Z. Du and B. Zhang, Polymer, 42, 9641(2001), DOI: 10.1016/S0032-3861(01)00450-5

18. M. Alagar, T. V. Thanikai Velan and A. Ashok Kumar, Polym. Comp., 21, 739(2000), DOI: 10.1295/polymj.36.848

19. M. Alagar, A. Ashok Kumar, K. P. O. Mahesh and K. Dinakaran, Eur. Polym. J., 36, 2449(2000), DOI: $10.1016 / \mathrm{S} 0014-3057(00) 00038-0$

20. M. Woo, L. B. Chen and J. C. Seferis, J. Mater. Sci., 22, 3665 (1987), DOI: 10.1007/BF01161475

21. D. S. Kim, M. J. Han and J. R. Lee, Polym. Eng. Sci., 35, 1353 (1995), DOI: 10.1002/pen.760351705

22. M. Pellegrino, M. Ezio, R. Giuseppe, R. Pieiro and S. Gennaro, J. Appl. Polym. Sci., 69, 1029 (1998), DOI: $10.1002 /($ SICI $) 1097-4628(19980801)$

23. H. L. Han, Y. C. Chen, K. Y. Li and K. H. Hsiesh, J. Appl. Polym. Sci., 70, 529 (1998), DOI: 10.1002/(SICI)1097-4628(19981017)

24. A. Ashok Kumar, M. Alagar and R. M. V. G. K. Rao, Mater. Manuf. Process., 16, 561(2001), DOI: 10.1081/AMP-100108527

25. A. Ashok Kumar, M. Alagar and R. M. V. G. K. Rao, J. Appl. Polym. Sci., 81, 2330(2010), DOI: 10.1002/app.1674

26. M. Abbate, P. Musto, E. Martuscelli and R. A. Giuseppe, Angew.Makromol. Chem., 241, 11(1996), DOI: $10.1002 /$ apmc.1996.052410102

27. K. Dinakaran and M. Alagar, J. Appl. Polym. Sci., 85, 2853(2002), DOI: 10.1002/app.10868

28. M. Alagar, T. V. Thanikai Velan, and A. Ashok Kumar, Poly. Comp., 21, 739(2004), DOI: $10.1002 /$ pc. 10228

29. M. E. Wright, D. A. Schorzman and L. E. Pence, Macromolecules, 33, 8611(2000), DOI: 10.1021/ma000916q

30. X. Z. Fang, Q. X. Li, Z. Wang, Z. H. Yang, L. X. Gao and M. X. Ding, J. Polym. Sci. Part: A. Poly. Chem., 42, 2130(2004), DOI: 10.1002/pola.20069

31. R. Chandra and L. Rajabi, J Macromol Sci Part: A. Poly. Rev., 37, 61(1997), DOI: 10.1080/15321799708014733

32. B. Dao, D. G. Hawthorne, J. H. Hodgkin, M. B. Jackson and T. C. Morton, High Perform. Polym., 8, 243 (1996), DOI: 10.1088/0954-0083/8/2/006

33. S. Tamai, T. Kuroki, A. Shibuya and A. Yamaguchi, Polymer, 42, 2373(2001), DOI: 10.1016/S0032-3861(00)00610-8

34. K. Dinakaran, R. Suresh Kumar and M. Alagar, Mater. Manuf. Proces., 20, 299(2005), DOI: 10.1081/AMP-200042098

35. Q. Yuan, F. Huang and Y. Jiao, J. Appl. Polym. Sci.,62, 459(1996), DOI: 10.1002/(SICI) 10974628(19961017)

36. D. P. Fasce and R. J. Williams, J.Polym. Bull., 34, 515 (1995), DOI: 10.1007/BF00423346

37. K. Varma and S. Sharma, Eur. Polym. J., 20, 1101 (1984), DOI: 10.1016/0014-3057(84)90136-8

38. O. K. Park, J. Y. Hwang, M. Goh, J. H. Lee, B. C. Ku and N. H. You, Macromolecules, 46 (9), 3505(2013), DOI: $10.1021 / \mathrm{ma} 400185 \mathrm{j}$

39. L. Dobiasova, V. Stary, P. Glogar and V. Valvoda, Carbon, 37, 421 (1999), DOI: 10.1016/S00086223(98)00207-3

40. S. M. Yuen C. C. M. MA, C. C. Teng, H. H. Wu, H. C. Kuan and C. L. Chiang, J. Polym. Sci. Part B: Polym.Phy., 46, 472 (2008), DOI: 10.1002/polb.21381

41. S. Premkumar, C. Karikal Chozan and M. Alagar, Eur. Polym. J., 44, 2599(2008), DOI: 10.1016/j.eurpolymj.2008.05.031

42. N. Amutha and M. Sarojadevi, J. Polym. Res., 15, 487 (2008), DOI: 10.1007/s10965-008-9193-3

43. J. H. Lee, K. Y. Rhee and J. H. Lee, Appl. Sur. Sci., 256, 7658(2010), DOI: 10.1016/j.apsusc.2010.06.023 
RASĀYAN J. Chem.

Vol. 12 | No. 1 |168 - 183| January - March | 2019

44. S. Jothibasu, S. Mohanamurugan and A. Vinod, Rasayan J. Chem., 11(3), 1255 (2018), DOI: 10.31788/RJC.2018.1133096

45. T. O. Siyanbola, A. F. Akinsola, O. R. Obanla, A. A. Adebisi, A. A. Akinsiku, I. O. Olanrewaju, K. O. Ogunniran, O. S. Taiwo, K. O. Ajanaku and O. A. Bamgboye, Rasayan J. Chem., 10(3), 1003(2017), DOI: 10.7324/RJC.2017.1031811

46. S. Wang, Z. Liang, T. Liu, B. Wang and C. Zhang, Nanotech., 17, 1551 (2006), DOI: 10.1088/09574484/17/6/003

47. T. Zhou, X. Wang, X. H. Liu and J. Z. Lai, Express Polym. Lett., 4, 217 (2010), DOI: 10.3144/expresspolymlett.2010.28

48. A. Selvaganapathi, M. Alagar and P. Gnanasundaram, Int. J. Plast. Technol., 5, S30 (2011), DOI: 10.1007/s12588-011-9004-2

49. D. Mathew, C. P. Reghunadhan Nair and K. N. Ninan, J. Appl. Polym. Sci.,74, 1675 (1999), DOI: 10.1002/(SICI)1097-4628(19991114)

50. M. Satheesh Chandran, M. Krishna, K. Salini, K. S. Rai, Int. J. Polym. Sci.,2010, 1 (2010), DOI: 10.1155/2010/987357

51. B. S. Kim, S. H. Bae, Y. H. Park and J. H. Kim, Macromol. Res., 15, 357 (2007), DOI: 10.1007/BF03218799

52. D. Bino Prince Raja, B. Stanly Jones Retnam, G. Antony Samuel Prabu and A. Alagu Sundaram, Rasayan J. Chem., 11(3), 990 (2018), DOI: 10.31788/RJC.2018.1133048

53. L. Devaraj Stephen, Rasayan J. Chem., 11(1), 155 (2018), DOI: 10.7324/RJC.2018.1111770

[RJC-4083/2018] 